\title{
Development of User-Friendly Web-Based Lost and Found System
}

\author{
Khairunnahar Suchana, Syed Md. Eftekhar Alam, Anika Tahsin Meem, \\ Manoshi Das Turjo, Mohammad Monirujjaman Khan* \\ Department of Electrical and Computer Engineering, North South University, Dhaka, Bangladesh \\ Email: *monirujjaman.khan@northsouth.edu
}

How to cite this paper: Suchana, K., Alam, S.Md.E., Meem, A.T., Turjo, M.D. and Khan, M.M. (2021) Development of User-Friendly Web-Based Lost and Found System. Journal of Software Engineering and Applications, 14, 575-590.

https://doi.org/10.4236/jsea.2021.1410034

Received: July 8, 2021

Accepted: October 16, 2021

Published: October 19, 2021

Copyright ( 2021 by author(s) and Scientific Research Publishing Inc. This work is licensed under the Creative Commons Attribution International License (CC BY 4.0).

http://creativecommons.org/licenses/by/4.0/

\begin{abstract}
People get lost every day, which is a very common incidence in our society. In particular, children, the elderly and mentally challenged people go missing all the time. This paper presents the development of web applications that can provide information and services to both a lost person's near and dear ones and also people who find the lost person. Using this developed web application, people who have lost a near and dear one can register via their email address and post all the information about the missing person, including photos, in the lost section. People who find someone can also register via their email addresses and post all the information about the found person, including photos, in the found section. There is a search panel where people can search for a lost or found person using their name, age, height, location, skin color, etc. There is also a contact system which can be used to contact the person who has lost or found someone via phone, email, or by connecting with their social media profile. Nowadays, when people lose someone or find someone, they report it to the police, advertise on television or in newspapers, and post it on all social media sites like Facebook and WhatsApp. But this web application provides a faster and enhanced way to find and connect with lost and found people.
\end{abstract}

\section{Keywords}

Information Service, Lost People, Web Application, Connecting People

\section{Introduction}

People getting lost is a very common incidence in our society. Especially in Bangladesh, where the population is more than 165 million and the population density is 1265 per $\mathrm{km}^{2}$ [1], it's very common for people to get lost. Online-based 
services make people's lives comfortable and hassle-free. Not only in Bangladesh but also in the whole world, there are so many online platforms for buying necessary things, tele-medicine and other services, but not enough platforms for finding lost people.

There are many problems people face when their near and dear one goes missing, such as filing police complaints, putting advertisements on television or in newspapers, etc. People also face many problems when they find a missing person, as they also need to file a police complaint and put an ad in the newspaper or on television. Numerous families are facing a problem of missing relatives. As a result, such families are living in trauma. The challenge faced is that there is difficulty in finding missing people using the current methods.

Over 10 million people around the world are missing, which has created a global "crisis", the International Committee of the Red Cross [2] said. Among all the missing persons, the number of missing children is on the higher side. In Canada, an estimated 45,288 children are reported missing each year. In Germany, an estimated 100,000 children are reported missing each year. In India, an estimated 96,000 children go missing each year. In the United Kingdom, an estimated 112,853 children are reported missing each year. In the United States, an estimated 460,000 children are reported missing each year [3]. The following Table 1 shows the missing persons by age group in UK.

According to the rights organization ASK, 91 people went missing in 2017, of which 65 are still missing [5]. These are just the reported cases. Many poor people don't even go to the police station to file complaints about their missing

Table 1. Missing Persons by age group in UK [4].

\begin{tabular}{ccccc}
\hline Age Group & $\begin{array}{c}\text { Missing Persons } \\
\text { (25\% sample) }\end{array}$ & $\begin{array}{c}\text { General } \\
\text { Population }\end{array}$ & $\begin{array}{c}\text { Percent of the } \\
\text { General Population }\end{array}$ & $\begin{array}{c}\text { (Versus } \\
\text { 24-year old's) }\end{array}$ \\
\hline 0 to 4 & 0.8 & 5.3 & 0.1 & 0.3 \\
5 to 9 & 1.0 & 5.8 & 0.1 & 0.3 \\
10 to 14 & 24.7 & 6.6 & 2.1 & 5.3 \\
15 to 19 & 46.7 & 6.9 & 3.9 & 9.8 \\
20 to 24 & 5.3 & 6.8 & 0.4 & - \\
25 to 29 & 2.6 & 6.0 & 0.3 & 0.8 \\
30 to 34 & 2.1 & 6.1 & 0.2 & 0.5 \\
35 to 39 & 1.8 & 6.9 & 0.2 & 0.5 \\
40 to 44 & 4.6 & 8.2 & 0.3 & 0.8 \\
45 to 49 & 2.8 & 8.1 & 0.2 & 0.5 \\
50 to 54 & 1.7 & 7.2 & 0.1 & 0.3 \\
55 to 59 & 2.1 & 6.3 & 0.2 & 0.5 \\
$60+$ & 4.0 & 19.7 & 0.1 & 0.3 \\
Total \% & 100.0 & 100.0 & 0.6 & - \\
Total & 724 & 504,560 & & - \\
\hline
\end{tabular}


near and dear ones because they want to avoid more hassles. Instead of taking police help or the help of the media, they try to find their missing relatives all by themselves for a few days, and after attempting for a few days, they just give up their search.

According to CNN, more than 1300 elderly people go missing in China every day, 500,000 per year, a news report claims. Senior citizens aged 65 or over account for up to $80 \%$ of the cases of missing elderly people, according to the Zhongmin Social Assistance under the Ministry of Civil Affairs [6]. The number is obviously huge, which can't be ignored.

Clearly, it can be seen that the need for a lost and found system is huge. The lost \& found system can play an important role in connecting lost people with their close ones.

There aren't any web-based lost $\&$ found services in Bangladesh that provide services and information related missing persons. Though Bangladesh Police has a missing person's database but it isn't active right now and even its active normal citizens aren't allowed to use it. That's why people still rely on the manual methods such as.

Police Investigations: In this mechanism, when a person goes missing, that person's relatives file a police report of missing person. In case of adults, police take missing report only after the person has been missing for more than $24 \mathrm{hrs}$. After filing police report, police start their own investigation which takes days, even sometimes the investigation takes months to solve.

Advertising on Media: This is a costly method as money is given for advertising about the details of missing people in television channels, newspapers and radios.

Miking \& poster: Not only in Bangladesh but also in many other countries people still use poster as a medium to let people notify about the missing person. And in Bangladesh and other Asiatic countries miking is used for letting people know all the details about the person who went missing.

Basically, the existing system for finding missing people is not dynamic. Our proposed system will overcome this problem.

\section{Existing Works}

There are many lost and found systems which are more concerned with things like mobile phones, watches, wallets, etc. The names of such systems are vFound, Simply Foundastic, etc. Most of these systems work in the same way. Both parties (who lost and who found) can report their lost and found belongings with details. They can also upload images of the belongings (if available). But there aren't any systems which are focused on lost people.

In the vFound [7] system, by registering with an email ID, people can use the system. A person who has lost any item needs to take a picture of that item and write a brief description of that product. The same rule applies to that person who finds an item and needs to take a picture of that item as well as describe the 
item and its condition. Using text matching and image matching algorithms, the system will find similarities and notify both the people who lost and found any item.

In the Simply Foundastic [8] system, users need to register using their email ID and list their lost items with a brief description and image of the lost item. A user who finds an item also needs to register using their email ID and write up all the information about the item, including the image. This is not a free web application. People who lose any item need to pay when the item is found.

In the Traista [9] mobile application, people can easily find their lost pet. It is a community-based mobile app where people can post lost and found items, including pets. Also, in this app, people can find the best spots to dine, relax, or be entertained. Also, in this app, people can open the map to see the on-going shopping deals at the local marketplace or the happy hour nearest to the hotel or hostel.

The US National Institute of Justice's National Missing and Unidentified Persons System (NamUs) is a national centralized repository and resource center for missing persons. This cannot be accessed by everyone around the world as it is limited only to US citizens [10]. NamUs contains three databases, namely:

The Missing Persons Database contains information about missing people that can be entered by anyone. However, before it appears as a case on NamUs, the information is verified. NamUs provides a user with a variety of resources, including the ability to print missing person's posters and receive free biometric collection and testing assistance.

The Unidentified Persons Database contains information entered by medical examiners and coroners. Unidentified persons are people who have died and whose bodies have not been identified. Anyone can search this database using characteristics such as sex, race, distinct body features and even dental information.

The Unclaimed Persons Database contains information about deceased persons who have been identified by name, but for whom no next of kin or family member has been identified or located to claim the body for burial or other disposition.

The main strength of NamUs is that it prevents falsification of information by providing free DNA testing, anthropology, odontology assistance and other forensic services.

\section{Methodology}

We developed a web application that will let people post about people who have been lost and found. Their brief description and image need to be included for better results. Figure 1 shows the flowchart of our system.

\subsection{Use Case}

Our system will work using the following steps: 


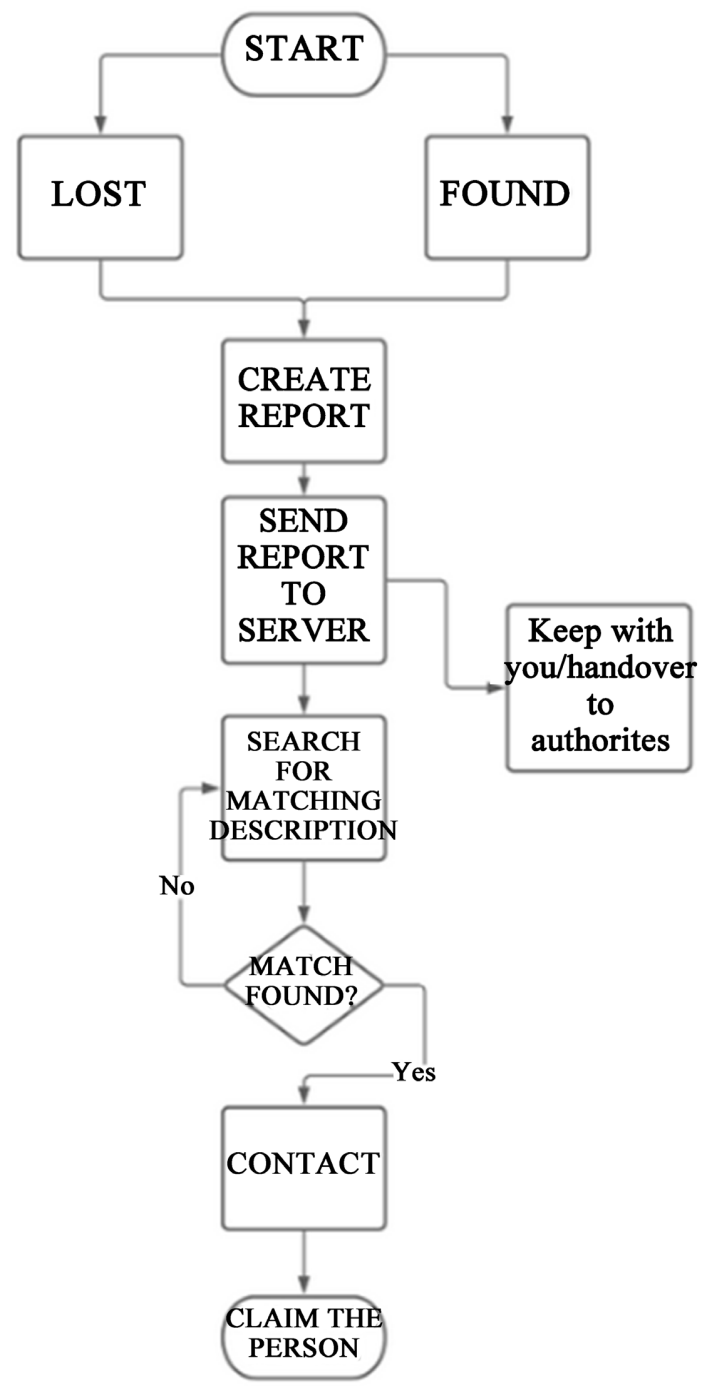

Figure 1. Flowchart of the lost \& found system.

1) The end user can open his own account providing his address so that people can contact him when required. The individual will be created automatically by the system.

2) The user can have two rules:

a) The user has found someone.

b) The user has lost someone.

3) If the user found someone who cannot provide his guardian information properly, then the user will create a found issue from his profile, providing the least information about the found person i.e., appearance, where found, photos etc.

4) If the user loses someone, s/he will also provide the detailed information and photos about the missing person.

5) Finally, our system's algorithm will try to text match between the lost and found issues; two best matching results will show up, thus allowing the people who lost and the people who found, can contact each other. The following Fig- 
ure 2 shows the use case diagram of the lost \& found system.

\subsubsection{Use Case for Lost}

In this system, users will be able to create profiles using their email address and phone number and will need to update their profiles with all the necessary information such as address, contact number, etc. Then they can post on the lost section about the lost person with as many details as possible, with two images of the missing person. Anyone can login using a username and password and search for a missing person in the lost section by providing information such as name, skin color, missing location, etc. All the posts that match the provided information will be shown. Figure 3 shows the use case diagram for searching lost person.

\subsubsection{Use Case for Found}

In the same way as for lost cases, if anyone finds a missing person, they need to

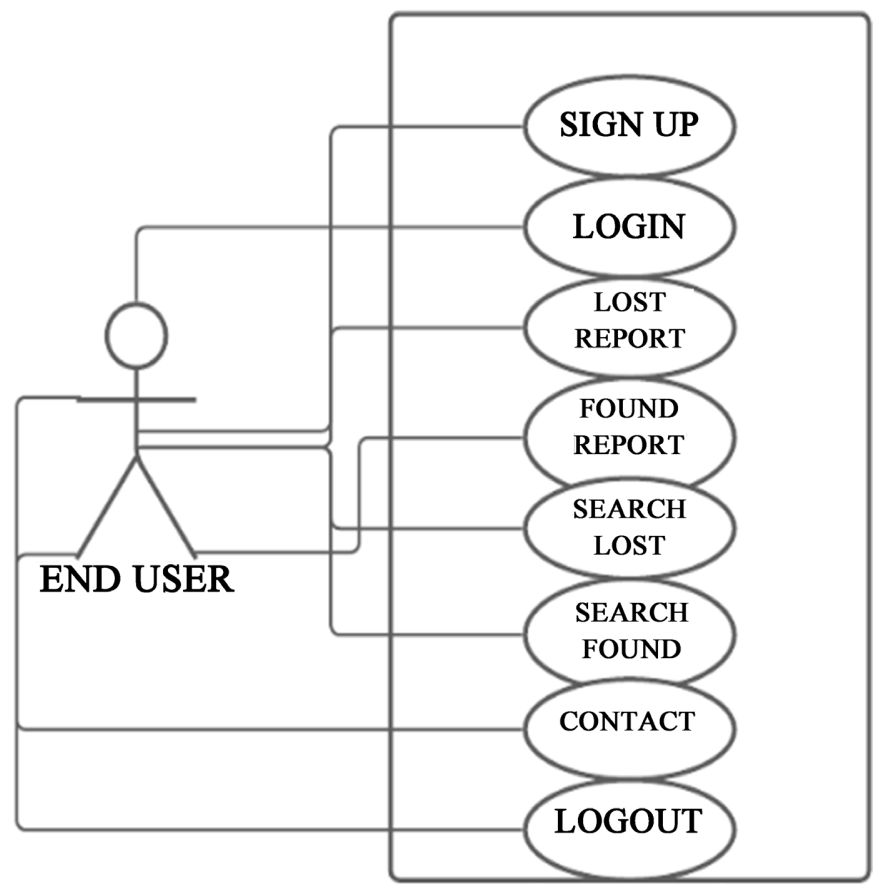

Figure 2. Use case diagram of lost \& found system.

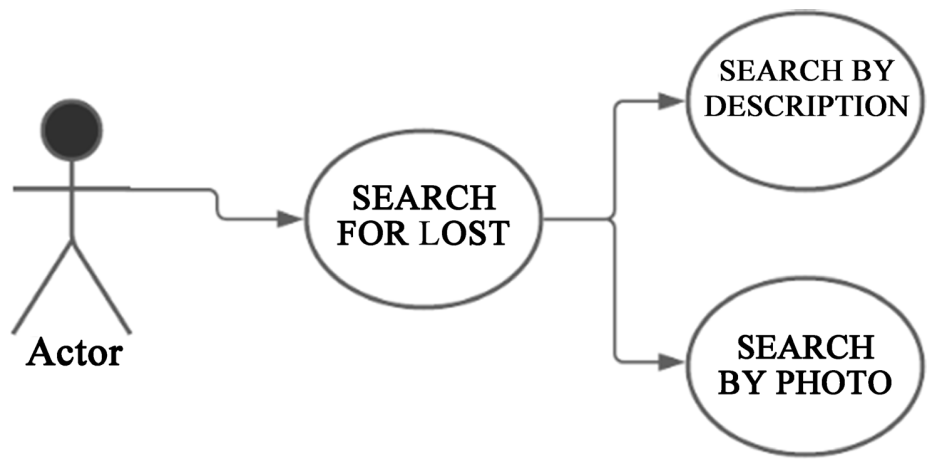

Figure 3. Use case diagram for lost case. 
register on the site using their email id and then, after login, they need to update their profile with all the necessary information. In found issues, the person can post a found case with all the available information such as name, parents' name, found location, two images, etc. Anyone registered on the site can search in the "found" section for found persons providing information such as names, skin color, missing location, etc. The best matching results will be shown. The following Figure 4 shows the use case diagram for found case scenario.

\subsection{Technology Used}

We used HTML, CSS, and the Bootstrap framework for frontend development. Bootstrap is one of the most popular CSS frameworks, which helps to develop responsive and mobile-first web pages [11]. We also used PHP for backend development. PHP (recursive acronym for PHP: Hypertext Preprocessor) is a popular open-source general-purpose scripting language that is ideal for web development and can be embedded in HTML [12]. For the database, we used the MySQL database. MySQL Database Service is a fully managed database service that enables organizations to deploy cloud-native applications using the world's most popular open-source database. It is $100 \%$ developed, managed and supported by the MySQL Team [13].

\section{Result and Discussion}

In this lost $\&$ found system, everybody needs to register and login to use the system. Users can view some of the web pages without login. Users can search for lost and found issues without login. But they cannot post any lost or found issues without signing up and logging in. Steps for using this lost and found system are given below.

\subsection{Home Page}

Our Home Page has a very simple and minimalistic view. It only has "Sign-Up" and "Login" options. Users need to sign up before using our system. Once a user is logged in into our system, s/he can use all of our system's features. Figure 5 shows the Home Page interface of our system. Upon choosing the SignUp or Login option, the user will be taken to a different page where they must provide

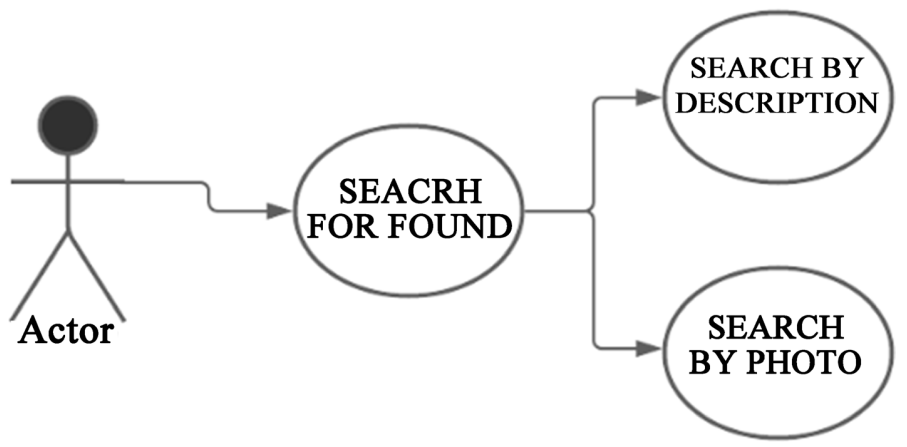

Figure 4. Use case diagram for found case. 
the necessary information to sign up or $\log$ in.

\subsection{Signup Form}

For signing up, users need to provide their first name, last name, username, email address, and password. Multiple users can be registered with the same name, but only one user can be registered via one email address and one username. Figure 6 shows the user registration form interface of our system.

\subsection{Login Form}

Users need to $\log$ in to use the application properly. Users must provide their

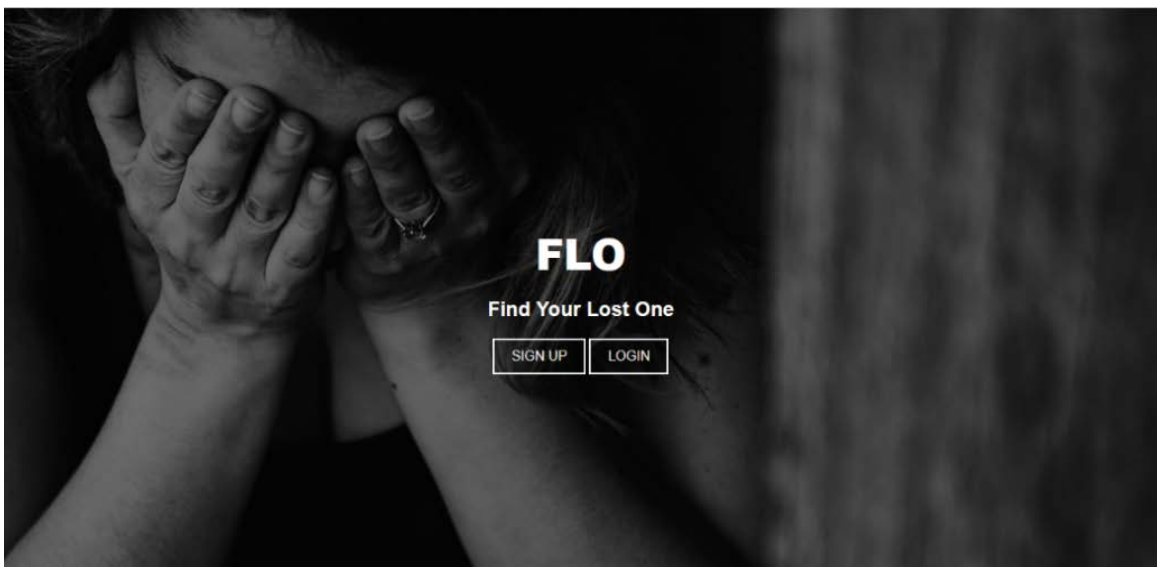

Figure 5. Front page of lost \& found system.

\section{FLO REGISTRATION FORM}

First Name

Last Name

Username

E-mail

a

Password

\section{Register $\rightarrow$}

Already have an account? Login Here

Figure 6. User registration form of lost \& found system. 
user's name and password for successful login. Without logging in, users cannot use the system and its features. Figure 7 shows the user login form where the users need to provide correct information for logging in successfully.

\subsection{User Profile Creation}

Once a user signs up to our system, a profile will be automatically created based on the given information. Once the user is logged-in to our system using their credentials, our system will automatically redirect him/her to the profile. Figure 8 shows the interface of the user profile. All the necessary information such as username, name, email, contact number, and address can be found here. There are also some additional features, such as Facebook communication, message sending, and phone contact.

From the profile, the user can then update his or her profile by providing

\section{FLO LOG-IN}

Username

Password

$\theta$

Get In $\rightarrow$

Don't have an account? Sign-In here

Figure 7. User login form of lost \& found system.

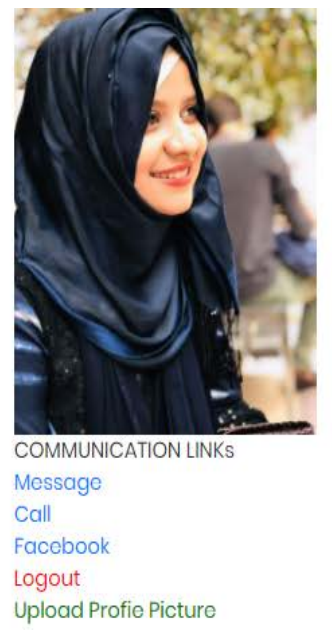

\section{Muntaha Bornil \\ Lost Issues Found Issues Edit Profile Matched Results.}

$\begin{array}{ll}\text { Username } & \text { Bornil } \\ \text { Name } & \text { Muntaha Bornil } \\ \text { Email } & \text { bornill5@gmail.com } \\ \text { Phone } & 01793625781\end{array}$

Address Flat and house: 171/1/h Area: 2255 Zip-Code: 1220 City: Dhaka State: Dhaka Country: Bangladesh

Figure 8. User profile page of lost \& found system. 
some extra information, such as contact information, address, gender, etc. A user can also change or add his or her profile picture from within his profile. We introduced this user profile option so that other users can contact them if they find or lose someone. Figure 9 shows the user profile updating interface.

\subsection{Create Lost or Found Issue}

Once the profile is created, the user can now report lost or found issues. If the user loses someone, she/he can create an issue about the person they lost. Similarly, if some user finds someone, she/he can also create an issue about the person they found. Figure 10 and Figure 11 show the lost issue creation interface and the found issue creation interface, respectively. After you provide detailed information about the lost or found person, our system will save this issue in our database and make it available for search.

\subsection{Searching}

As shown in Figure 12, we have a total of four search options. The first two options are for basic searching, where users need only provide their names for searching. The next two options are for advanced searching where users need to provide multiple information such as skin tone, age, parents' name etc.

\subsubsection{Basic Search Options}

The first two search options are only useful when both parties know the name of

\section{UPDATE YOUR PROFILE}

\begin{tabular}{ll} 
Contact No. \\
\hline Flat and House No. & Road and Area \\
\hline City & Zip-Code \\
\hline State & Country \\
\hline Gender
\end{tabular}

\section{Done}

Figure 9. Profile update interface of lost \& found system. 


\section{LOST ISSUE ENTRY FORM}

\begin{tabular}{|c|c|}
\hline Muntaha Mahnur & \\
\hline Mossarof Hossain & Shayla Sharmin \\
\hline 6 & 4 \\
\hline $15 / 09 / 20$ & Dhaka \\
\hline White & Frock \\
\hline shaymoly road no 2 , el & 01793625781 \\
\hline $\mathrm{n} / \mathrm{a}$ & \\
\hline
\end{tabular}

Submit $\rightarrow$

Figure 10. Lost issue creation form of lost \& found system.

\section{FLO FOUND ISSUE FORM}

\begin{tabular}{|c|c|}
\hline Full Name & \\
\hline Father's Name & Mother's Name \\
\hline Age & Height \\
\hline found Date & found Location \\
\hline Skin-Tone & Dress \\
\hline Detailed Address & Contact No. \\
\hline
\end{tabular}

\section{Submit $\rightarrow$}

Figure 11. Found issue creation form of lost \& found system. 
Search Found Issues By Query

Search Lost Issues By Query

\section{Advanced Search For Found}

\section{Advanced Search For Lost}

Figure 12. Basic search options of lost \& found system.

the person they lost or found. The user can search for and find issues by querying if she or he has lost someone, or to check if someone has found the person the user has lost. Similarly, a user can search lost issues by query if she/he found someone, to check if someone lost the person.

\subsubsection{Advanced Search Options}

With this option, one can search based on what information she/he has. A user can only search by height, age, skin-tone, dress, lost/found location etc. A user can use all the input fields or some of some of those or even only one field. Figure 13 and Figure 14 show the advanced search engine for lost and found respectively.

\subsection{Matching Results}

With our different search options, if the result matches with our existing entries, the result will be shown to the user. This page will show all the information along with the matched result. The user can find both the person she or he is looking for along with the person who updated the issue. All the contact information will be shown so that users can contact the person who created the issue. Figure 15 shows the matching result profile of a lost person. The profile will contain the necessary information such as name, age, parent's name, address, etc. The matching result for the found person will also be the same.

Following the steps (4.1 to 4.7) stated above, any user can use our lost $\&$ found system very easily.

\subsection{Social Impact}

With the technology and internet being available to mass people, we think it will 


\section{FLO ADVANCED SEARCH \\ ENGINE \\ SEARCH FOR LOST PEOPLE}

The more the field input, the narrower the results, the less the inputs the more possibility to find the results.

Full Name

Father's Name

Mother's Name

Age

Height

Lost Location

Skin-Tone

Dress

\section{Search.}

Search Result:

Figure 13. Advanced search for lost person.

\section{FLO ADVANCED SEARCH ENGINE SEARCH FOR FOUND PEOPLE}

\begin{tabular}{l} 
The more the field input, the narrower the \\
results, the less the inputs the more possibility to \\
find the results. \\
Full Name \\
Father's Name \\
Age Height \\
\hline Lost Location \\
\hline Skin-Tone
\end{tabular}

\section{Search.}

Search Result:

Figure 14. Advanced search for found person. 


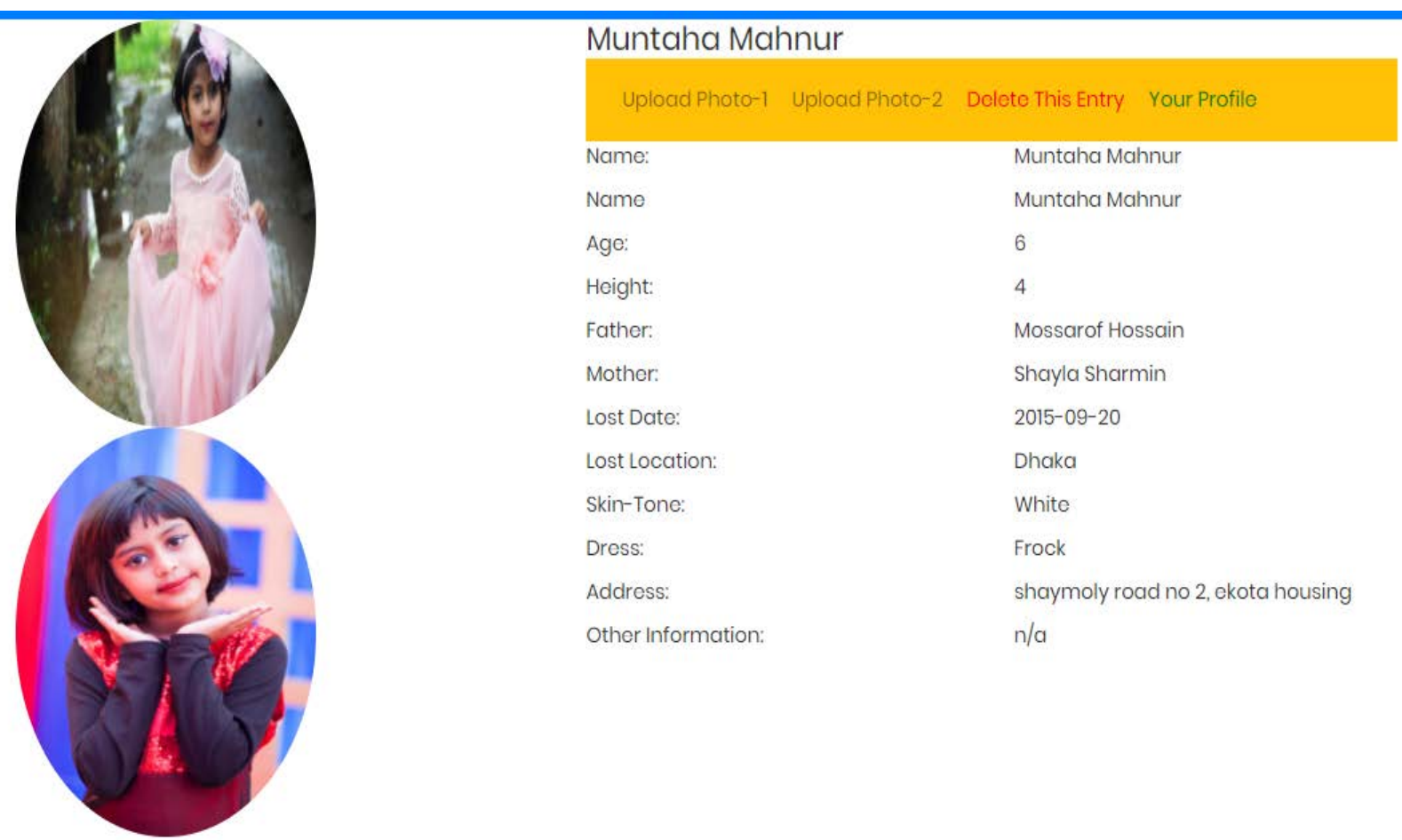

Figure 15. Search result of Lost person.

be a great help to the people who lost someone. It's rather a systematic approach which will reduce the hassle of miking, distributing the leaflets etc. Nowadays, people have easy access to the internet. That's why we think our system will be very beneficial for society, as people can find their missing close people through our system. With this system, the law enforcement agencies can also get help to find a certain person they're looking for. We just built a system, but it could be used for several purposes with some modifications. Our effort is successful if only a tiny portion of people can get help from our system without spending extra money or physical effort.

\subsection{Sustainability}

We are also planning to integrate the image recognition method into our system so that people can find one easily just by searching for it. With the state-ofthe-art technology and the user-friendly, snappy, fast system with great reliability, we think this should be the future. Moreover, when people lose someone, they try in every possible way to get the lost person back. With more people getting help from the system, the more user engagement we will get day by day.

\section{Conclusion}

People are missing all the time all around the world. The number of missing people is rising every single day. So, the necessity of lost \& found services has risen as it's not possible for police or other authorities to tackle this problem alone. We have analyzed and researched some solutions and found that online- 
based solutions will be the best in this situation. Nowadays, people greatly rely on the internet for everything. From groceries to tele-medicine, banking to online transactions, everything is being done online. So, for this problem we also need an online solution. It's not feasible for people to look for their missing near and dear ones by walking on the road. But our system is very beneficial for all kinds of people. If anyone goes missing and their relatives post about the missing person online with all the necessary details, then everyone may keep their eyes open to find the missing person. If found, they can also post in our system so those who are lost can easily connect with the missing person. This web-based application will create a connection between lost and found people. That's why we think our lost \& found system is an innovative system and will provide a lot of help to society. As mentioned above at 4.9 , image processing will be added in our system, so that if anyone finds an underage child or physical or mentally challenged person or any old person who are unable to tell their name or any other information, the person who found can just click a picture and post in our system and also can search in the missing section using image. We will also make the system automatically send messages and emails to the users if the system found some matching result with the lost or found issue that the user created.

\section{Acknowledgements}

We would like to give special thanks to the authorities and the Department of Electrical and Computer Engineering of North South University for giving us the resources and facilities to do this project.

\section{Conflicts of Interest}

The authors declare no conflicts of interest regarding the publication of this paper.

\section{References}

[1] Worldometers-info (2021) Bangladesh Population. https://www.worldometers.info/world-population/bangladesh-population/

[2] Lederer, E.M. (2018) Red Cross: Over 100,000 Missing People Is a Global Crisis. AP News. https://apnews.com/article/efa2b8e6d21e42c9ae06e7787f18fc49

[3] International Centre for Missing \& Exploited Children (2020) Global Missing Children Network. https://globalmissingkids.org/awareness/missing-children-statistics/

[4] Kiepal, L., Carrington, P.J. and Dawson, M. (2012) Missing Persons and Social Exclusion. Canadian Journal of Sociology, 37, 137-168.

[5] bdnews24.com. (2017) 91 Went Missing in 2017, 65 Still Unaccounted for, Says ASK in Year-End Report.

https://bdnews24.com/bangladesh/2017/12/31/91-went-missing-in-2017-65-still-un accounted-for-says-ask-in-year-end-report

[6] Griffiths, J. and Wang, S. (2016) 500,000 Elderly People Go Missing in China Every Year. CNN Health. https://edition.cnn.com/2016/10/12/asia/china-elderly-missing/index.html 
[7] vFound Private Limited (2020) https://www.vfound.io/

[8] Lost \& Found Software (2020) https://lostandfoundsoftware.com/

[9] Traista Website \& App. (2020) https://traista.com/

[10] National Missing and Unidentified Persons System (2020) NamUs. https://www.namus.gov/

[11] FSDFDSA Bootstrap Team (2020) Build Fast, Responsive Sites with Bootstrap. https://getbootstrap.com/

[12] The PHP Group (2020) What Is PHP? https://www.php.net/manual/en/intro-whatis.php

[13] Oracle Corporation (2020) MySQL Database Service. https://www.mysql.com/ 